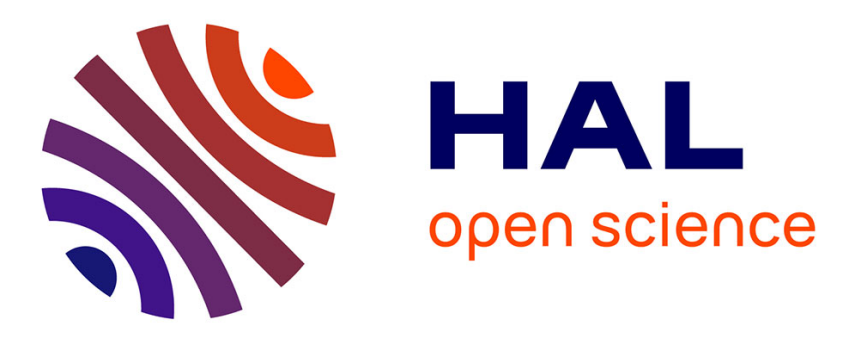

\title{
Specific language impairment as systemic developmental disorders
}

Christophe Parisse, Christelle Maillart

\section{To cite this version:}

Christophe Parisse, Christelle Maillart. Specific language impairment as systemic developmental disorders. Journal of Neurolinguistics, 2009, 22, pp.109-122. 10.1016/j.jneuroling.2008.07.004 . halshs00353028

\section{HAL Id: halshs-00353028 \\ https://shs.hal.science/halshs-00353028}

Submitted on 14 Jan 2009

HAL is a multi-disciplinary open access archive for the deposit and dissemination of scientific research documents, whether they are published or not. The documents may come from teaching and research institutions in France or abroad, or from public or private research centers.
L'archive ouverte pluridisciplinaire HAL, est destinée au dépôt et à la diffusion de documents scientifiques de niveau recherche, publiés ou non, émanant des établissements d'enseignement et de recherche français ou étrangers, des laboratoires publics ou privés. 
Specific language impairment as systemic developmental disorders

Christophe Parisse $^{1}$ and Christelle Maillart ${ }^{2}$

1- INSERM-MoDyCo, CNRS, Paris X Nanterre University

2- University of Liège 


\begin{abstract}
Specific Language Impairment (SLI) is a disorder characterised by slow, abnormal language development. Most children with this disorder do not present any other cognitive or neurological deficits. There are many different pathological developmental profiles and switches from one profile to another often occur. An alternative would be to consider SLI as a generic name covering three developmental language disorders: developmental verbal dyspraxia, linguistic dysphasia, and pragmatic language impairment.

The underlying cause of SLI is unknown and the numerous studies on the subject suggest that there is no single cause. We suggest that SLI is the result of an abnormal development of the language system, occurring when more than one part of the system fails, thus blocking the system's natural compensation mechanisms. Since compensation also hinders linguistic evaluation, one possibility for diagnosis and remediation control is to assess basic cognitive abilities by non-linguistic means whenever possible. Neurological plausible bases for language and language development should also be taken into account to offer new hypotheses and research issues for future work on SLI.
\end{abstract}

Keywords: specific language impairment, language system, developmental disorder 


\section{Introduction}

Not all children learn language effortlessly. Some of them, around 7\% (Tomblin \& Zhang, 1999, p. 220) in kindergarten, present some kind of Specific Language Impairment (SLI). These problems affect both expressive development (e.g. errors in sound production, limited vocabulary, errors in tense, difficulty recalling words or producing sentences with developmentally appropriate length and complexity) and receptive development (e.g. difficulty

understanding words or sentences). The language disorder may be specific or it may be associated with a more general learning disability, autism or physical or neurological damage (such as cleft palate, cerebral palsy or head injury). If untreated, these disorders can have an impact on school performance and career choices over the long term.

SLI, a condition that has sometimes been called developmental dysphasia (DD), but is also known as language-learning impairment or developmental language disorder, belongs to the category of specific disorders: the language level observed is substantially below the nonverbal intellectual capacity. This limitation on language abilities cannot be explained by any obvious factor such as hearing impairment, low verbal intelligence, neurological damage or psychological problems (Bishop, 1992; Tallal, Stark, \& Mellits, 1985). Thus, the criteria for SLI are primarily exclusionary. Children with SLI have been shown to present heterogeneous linguistic symptoms (for an overview, see Bortolini, Leonard, \& Caselli, 1998). To account for this heterogeneity, several classification systems based on clinical observation or empirical studies have tried to assign children to homogeneous sub-groups (Bishop \& Rosenbloom, 1987; Korkman \& Hakkinen-Rihu, 1994; Rapin \& Allen, 1983). For instance, Rapin and Allen (Rapin \& Allen, 1983) described three sub-types of developmental disorders and six profiles of language problems based on linguistic analyses of phonological, lexical, morphosyntactic or pragmatic abilities. 
They distinguished mixed receptive-expressive disorders (including ‘verbal auditory agnosia’ and 'phonologic-syntactic deficit disorder'), expressive disorders (including 'verbal dyspraxia' and 'speech programming deficit disorder'), and higher-order processing disorders (including 'lexical deficit disorder' and 'semantic-pragmatic disorder'). Five of the six profiles described have found empirical confirmation in a study (Gina Conti-Ramsden, Crutchley, \& Botting, 1997) that combined clinical and test information. A cluster analysis was performed on the children's performance and produced six groups of children. One of the groups had no match with Rapin and Allen's categories because it was composed of children who appeared to be performing within the normal range. In contrast, however, the 'verbal auditory agnosia' group described by Rapin and Allen was not found.

\section{Limits of the definition of SLI}

The same generic name (SLI or DD) is used to characterise very different populations, e.g. very young children (3 years) who do not initiate language acquisition normally (see for example, Fey \& Loeb, 2002); teenagers (15-16 years) after several years of language remediation; children presenting a minor language disorder (-1 standard deviation for a language test battery, see Ellis Weismer, Evans, \& Hesketh, 1999) or a more acute disorder (-1,5 standard deviation for a language test battery, see H. K. J. van der Lely \& Ullman, 2001), or children presenting expressive (and receptive) disorders. Several linguistic tests have been proposed as potential psycholinguistic markers for such language disorders. Tests involving the repetition of 'pseudowords’ (Bishop, North, \& Donlan, 1996) or the production of verbal morphology in obligatory contexts (Rice \& Wexler, 1995) seem particularly interesting candidates, even though they are still subject to discussion (G. Conti-Ramsden, Botting, \& Faragher, 2001). Indeed, those tests cannot really distinguish children presenting specific language disorders from those with other 
language problems. For example, children affected by Down's syndrome find it particularly difficult to repeat pseudo-words (Jarrold, Baddeley, \& Hewes, 2000) and children learning a second language fail verbal morphology tests badly (Paradis \& Crago, 2000).

This lack of specificity reminds us of other criticisms concerning the exclusion criteria traditionally used for SLI. The strict integrity of nonverbal capacity (IQp > 86 or 1 standard deviation) seems very demanding and may not really be justified. Indeed, studies have shown that neither linguistic characteristics (Tomblin \& Zhang, 1999) nor efficiency of language reeducation (Fey, Long, \& Cleave, 1994 ) can distinguish SLI children with an IQ of between 70 and 85 from children whose IQ is superior to 85 . The same pattern of linguistic impairment may be seen in children with low or high nonverbal IQs. Another problem concerns the development of intellectual capacities, even nonverbal ones, with age: when a language deficit persists, it becomes increasingly difficult to obtain a nonverbal score close to the average. It is not unusual to observe deterioration in IQ, even nonverbal IQ, in those cases. This change can be so significant that if children were evaluated based only on their most recent nonverbal capabilities, some of them would be excluded from the sample groups because of their low IQ scores (Bishop, Bright, James, Bishop, \& Van der Lely, 2000).

It is very important to take into consideration the dynamic aspects of developmental pathologies. Indeed, aging induces important changes on both the verbal and nonverbal levels. Longitudinal studies focusing on linguistic classification (see below) have shown that during language development, a child may frequently switch from one sub-category to another (Bishop \& Edmunson, 1987; Botting \& Conti-Ramsden, 2004). For instance, 45\% of children followed longitudinally by Botting and Conti-Ramsden (2004) changed clusters between time 1 (7 years old) and time 2 (8 years old). Longitudinal studies confirm that affected individuals may be able to compensate for their problem, so that their underlying difficulties can only be observed by 
taking a history or using specific tests. This raises doubts about the existence of sub-categories corresponding to different impairments, and supports the hypothesis that the symptoms of a given problem may vary as a function of development.

\section{Cause of SLI}

The cause of SLI is unknown, but it appears to run in families. If a child has SLI, there is a $25 \%$ chance that another family member will be affected. As there seems to be no relationship between SLI and the level of language input given to a child or the family's social or economic class, the environment alone cannot be causing the language impairments. SLI is complex: it does not appear to be inherited as a single gene disorder; instead, it may be caused by a number of different genes that combine and interact with environmental factors to produce an overall risk factor for developing language problems (Bishop, 2006).

Different hypotheses have been proposed to account for the language problems experienced by children with SLI. In the view of some authors (Adams \& Gathercole, 2000), these children present an impairment in a system that specialises in holding material in memory for short periods of time (phonological short-term memory). Other authors believe that the deficit may affect the perception of auditory input more generally (Tallal, Stark, \& Mellits, 1985), may be specific to certain grammatical difficulties (e. g. H. K. J. van der Lely, 1999) or may concern a more general processing or capacity limitation (Ellis Weismer, Evans, \& Hesketh, 1999). These hypotheses seek to reflect the underlying neurodevelopmental factors thought to play a causal role in SLI. Indeed, the only way to explain the changes in linguistic profile and variable performance of children with SLI is to go beyond the description of symptoms in an attempt to identify the underlying alterations, which are not necessarily linguistic. One should not expect a one-to-one relation between the hypothesised causes and sub-types of language disorders. 'SLI' is 
a disorder resulting from multiple underlying deficits. As Bishop suggested (2006:220), 'There may be multiple routes to effective language acquisition, and if one route is blocked, another can be usually be found. However, if two or more routes are blocked, then language learning will be compromised.’

Therefore, to understand the potential compensation mechanism that children with SLI are using, and to explain their variable performance, it would be very interesting to focus more on the evaluation of non-linguistic abilities. Most of those children have a number of associated problems (e.g. attentional or executive impairment, etc.) which are not really considered in the usual classifications. Certain combinations of linguistic and non-linguistic impairments could be used as more reliable markers for differentiated diagnoses or to improve predictions concerning the children's development.

\section{Proposed approach}

When one encounters a very complex problem that appears impossible to solve, it is often because it is not clearly described or the point of view is not correct.

Our proposal is that SLI is not a specific disorder or even a single syndrome but rather a set of syndromes that all correspond to a certain pathological state of the language system. This means that one should only use the term SLI in the plural to designate a whole set of developmental disorders that involve some type of language pathology. We agree with Bishop (2004) that some sub-types of developmental speech and language impairment can be distinguished based on agreement among clinicians. It would be more useful to talk about developmental verbal dyspraxia (DVD), linguistic dysphasia (typical SLI in Bishop’s terminology) (LD), and pragmatic developmental impairment or, following Bishop, 'pragmatic language impairment' (PLI). These three syndromes can be adequately described and are clearly 
differentiated from one another (see below), and children diagnosed with one syndrome will not change their pathological status during their development. They will either improve or remain stable, but within the same syndrome. Classification into three syndromes instead of a larger allinclusive category offers the advantage that remediation and scientific research would be much more clearly focused and different studies would be easier to compare with one another. Bishop proposed a fourth category called 'severe receptive language disorder' to cover a very rare set of children who have such severe problems understanding language that they are initially thought to be deaf (verbal auditory agnosia). Like Botting and Conti-Ramsden (2004), we never have encountered such children. So we will not discuss this last category.

Each of the three syndromes corresponds to a specific state of the language system. However, this does not mean that each syndrome corresponds to a clear-cut disorder. On the contrary, in each case, the language system remains what it always is: a very complex and powerful system built on multiple basic abilities with strong compensatory abilities. Compensation is so strong that it is unlikely that a deficit in a single basic ability can make the whole system deficient. However, multiple deficits (even small ones if there are enough of them) could result in a deviation of the system towards a pathological state, a certain type of dysphasia. The existence of three clearly differentiated pathological states is linked to the properties of the system. The system may stabilise in three different possible states which correspond to some of its inner properties (the physical interface, the organisation of language forms, the communicative functions of language).

\section{Linguistic and non-linguistic profiles}

This section starts with the clinical grouping proposed by Bishop, which is extended in light of the clinical observations collected in our linguistic evaluation practice. To illustrate the interest 
of combining nonverbal evaluations with the linguistic assessment, the profiles obtained using a nonverbal scale will be presented and discussed. We have chosen to describe the profiles obtained with the Hiskey Nebraska Test of Learning Aptitude because this tool seems to better differentiate profiles according to the proposed linguistic classification, compared to other more recent tools such as WISC IV. The Hiskey Nebraska Test of Learning Aptitude (HNTLA; Hiskey, 1966) is an old battery designed to be used with hearing-impaired children from the ages of three to sixteen. As it can be administered without verbal instructions, this test is particularly appropriate for a language-impaired population. The test consists of 124 items arranged in order of increasing difficulty, which are grouped into 12 sub-tests: bead patterns, memory for colour, picture identification, pictorial association, paper folding, visual attention span, block patterns, completion of drawings, memory for digits, puzzle blocks, picture analogies and spatial reasoning. Each sub-test gives a learning age, which allows one to determine a general profile. A subset of tests was presented to the children, depending on their age.

Four different profiles can be distinguished, three of which belong to SLI:

I. Non-specific language delay

From the linguistic point of view, the children in this category present a rather homogeneous profile, with limited differences between the linguistic levels. Their performance at the phonological, lexical and morphosyntactic levels is similar and poorer than would be expected of children with this chronological age. Children in this category do not present communication disorders and very seldom present verbal hypospontaneity. Their HNTLA results are also more homogeneous, and lower than their chronological age. Their behaviour cannot be categorised as SLI, because their disorders are not specific to language. 


\section{Typical SLI}

According to Bishop, this group focuses on children who have disproportionate problems with grammatical development. This syndrome may be accompanied by major lexical-semantic problems or by difficulties in perceiving oral language at the rate at which it is normally produced which lead to a slow and distorted acquisition of phonology and syntax. The profile obtained on the HNTLA test seems typical, with a clear gap between the items assessing sequential memory (e.g. bead patterns, folding paper, visual attention, colour or number memory), on which performance is poorer, and the other sub-tests, on which the children perform in line with or superior to the norm.

III. Developmental verbal dyspraxia

These children present speech output problems, i.e. some difficulty in programming movements that cannot be explained in terms of muscle weakness or sensory loss. The children can imitate individual movements or speech sounds, but are not able to produce longer sequences. They frequently fail at the items of the HNTLA test that require high coordination capabilities (e.g. folding paper or arranging blocks). Poor graphic abilities can be observed in the drawing task. Performance on the other sub-tests is in line with or superior to the norm.

IV. Pragmatic language impairment

Children with pragmatic language impairment have problems using language appropriately in a given context. Their comprehension is overly literal and their answers lack coherence in conversation or narrative speech. These children do not compensate for their language difficulties by developing a rich repertoire of nonverbal communication. They share a number of features with high-functioning autistic children. Their profile on the HNTLA battery is erratic: on several sub-tests (e.g. bead patterns and memory of colours), they are very much better than the norm, while on other ones, based on semantic content (e.g. pictorial association, completion of 
drawings, picture analogies), they fail. Their performance on the other sub-tests is within the normal range.

\section{Rethinking the evaluation of SLI}

We have argued that SLI is not a single syndrome, but a generic term that covers certain states of the human linguistic system, all of which result from abnormal developmental trajectories with regard to language acquisition. As with all other systemic behaviours, human language is the result of a large set of abilities that are not necessarily specific to language and that interact together so that the whole is bigger than the parts. This last aspect is problematic when it comes to the evaluation of language. If the whole is greater than the sum of its parts, this means that no linguistic ability is independent of any other linguistic abilities. For example, when evaluating the children's phonological performance, the frequency of phonological structures and phonotactics are not independent of the characteristics of the lexicon and morphosyntax, nor of the speaker's language use or social situation. The children's results will depend on their other linguistic performances. This does not mean that purely linguistic evaluation is impossible. For example, using non-words or unknown words when testing phonological knowledge minimises the importance of semantics and complex syntax. However, this would not be enough to ensure a clear description of the children's deficits.

An alternative would be to test the children's performance outside the linguistic system when this is possible. Indeed, non-linguistic performances are usually independent of other nonlinguistic performances, unless they share some biological or cognitive properties. For example, children's performance on frequency discrimination should be independent of their performance on spatial working memory. Using a large set of non-linguistic abilities, it should be possible to precisely characterise the children's deficits and to differentiate between different sub-types of 
SLI. If the non-linguistic abilities can be linked to linguistic abilities (for example, frequency discrimination between pure sounds or between vowels), this would help us to understand how the language systems works and to plan and organise language remediation.

The idea behind this approach does not come out of nowhere. Ullman and Pierpont (2005) made the same proposal regarding procedural memory. Their idea was that procedural memory is the hidden problem behind many language disorders and they hypothesised that this was not a language-specific deficit but could be found in other cognitive domains. Other results in the literature are compatible with this hypothesis. A number of authors have hypothesised that the children's deficit could be linked to an impairment in peripheral or instrumental abilities. Many of these abilities can be tested in both linguistic and non-linguistic ways. Some of them, such as categorical perception, were first thought to be language-specific (Eimas, Siqueland, Jusczyk, \& Vigorito, 1971). However, later results have shown that this ability is also found in non-human primates (Morse, Molfese, Laughlin, Linnville, \& Wetzel, 1987). Among humans, this ability is also applied in non-linguistic tasks (Jusczyk, Rosner, Cutting, Foard, \& Smith, 1977). This same issue of language-specificity can be raised about one of the most fundamental linguistic abilities: syntax. The variability among the languages of the world and the diversity of language development make it difficult to identify core syntactic knowledge in the cognitive system. Hauser, Chomsky, and Fitch (2002) proposed that innate human language abilities could be reduced to mere recursion. This idea is not shared by all researchers (see for example Karlsson, 2007), but whether recursion does or does not exist or is limited to a certain depth level, it does not change the fact that recursion is also used in other cognitive domains such as reasoning, so it should be possible to test this ability non-linguistically.

Specifically, we propose that a whole set of abilities should be tested both nonlinguistically and linguistically. As of now, our proposal is a research programme. The abilities 
that we propose for testing - mainly based on previous work from the literature - are numerous and correspond to many different tests. They could not be practically used in day-to-day clinical practice, but hopefully a smaller set could be devised later on using only the most useful and sensitive testing procedures. In particular, only one ability from a set of closely correlated abilities needs to be tested, and abilities that characterise very small groups of children are not useful for screening procedures. Very precise and thorough testing procedures would be limited to research or very special cases in practice. Also, as this is a research programme, linguistic evaluation remains necessary, if only so we can judge language performances, and also because some of the children's abilities may be specific to language. Later, it is possible that some linguistic evaluations will prove unnecessary, having been superseded by non-linguistic evaluations.

\section{A framework for research and SLI evaluation}

A large body of literature links language deficits and non-linguistic abilities. We will use the results from that literature to propose a framework for research in the evaluation of SLI. We also wish to structure this framework and hope not to forget any possible avenues for research. For these reasons, we have tried to cover three main aspects of language: peripheral input, peripheral output and central processes.

\subsection{Peripheral input}

Numerous proposals have linked problems in peripheral input with language development disorders. The main theme of some of these studies is developmental dyslexia, rather than SLI, but it is most likely that severe forms of dyslexia include dysphasic behaviour. The best-known approach is Tallal's hypothesis that there is an impairment in the processing of fast sound transitions (Tallal, Stark, \& Mellits, 1985). Recent work (Bishop, Carlyon, Deeks, \& Bishop, 
1999) has demonstrated that this cannot explain all dysphasic behaviours, but problems processing fast sound changes could be among the features that lead to SLI in a child. Other authors (McArthur \& Bishop, 2002; McArthur \& Bishop, 2004) have proposed an alternative to this deficit, namely difficulty with frequency discrimination. One characteristic of this behaviour is that it changes with age. Young children with SLI seem to have this deficit, but older children with the same disorder are able to catch up - but not in their language performance. A final proposal regarding peripheral input is a deficit affecting categorical perception (Serniclaes, Van Heghe, Mousty, Carré, \& Sprenger-Charolles, 2004). Children with developmental dyslexia appear to have a categorisation system that is too powerful and cannot produce the large phonemic classes that are required for correct phonemic representations. All these abilities, if deficient, are prone to generate problems in phonemic representations, which are a weak point in children with SLI (Criddle \& Durkin, 2001). None of these three abilities is specific to linguistic data and all can be tested with non-linguistic material. Problem with categorical perception could also be linked to limitations due to processing demands (Coady, Kluender, \& Evans, 2005).

\subsection{Peripheral output}

Peripheral output is not the best studied of the sub-systems, although there are several candidates that could fall into this category. Motor programming (Webster et al., 2006; Webster, Majnemer, Platt, \& Shevell, 2005) and production of sequential structures (Howard, Howard, Japikse, \& Eden, 2006) are linked to language problems and could be tested with linguistic and gestural material.

\subsection{Central processes}

A large set of central processes or characteristics have been singled out as being linked to deficits in language development. They include working memory, procedural memory, long-term 
memory, computation load and complexity, sequential processing, and categorisation. All of these abilities are used to various extents in different parts of the language system: lexicon, grammar, semantics, and pragmatics.

Working memory is the only central process that has already been extensively studied in relation to language impairment. The relationship between language deficits and working memory has been demonstrated in numerous studies (see Adams \& Gathercole, 2000), but no fully satisfactory explanation of this relationship has yet been provided (Botting \& Conti Ramsden, 2001). Most working memory difficulties involve phonological working memory. Difficulties in functional working memory are likely to exist as well but the relation to children with SLI performances is unclear (Montgomery, 2000, , 2003), as example, the relationship between children's difficulties with complex tasks and their processing speed (L. B. Leonard et al., 2007; Montgomery \& Windsor, 2007). As is the case with frequency discrimination, there is an interaction with children's general development. A phonological working memory deficit is linked to deficits in non-linguistic abilities (Archibald \& Gathercole, 2007; Bavin, Wilson, Maruff, \& Sleeman, 2005; Hick, Botting, \& Conti-Ramsden, 2005). Functional magnetic resonance imaging (fMRI) with a verbal working memory task demonstrated that children with SLI exhibited a less functional brain network, with was interpreted as supporting the notion that non-linguistic systems play a role in SLI (Ellis Weismer, Plante, Jones, \& Tomblin, 2005).

Procedural memory has been hypothesised to be a cause of grammatical disorders (Ullman \& Pierpont, 2005). Long-term memory is known to be deficient in dyslexia (Nicolson \& Fawcett, 2000), and it could also play a role in SLI. Computation load has often been singled out as a key problem for children with SLI (Bavin, Wilson, Maruff, \& Sleeman, 2005), but whether this problem is specific to language remains to be seen. Problems with sequential material are often mentioned in connection with phonology, but they are also important for syntax and could exist 
in other dimensions of cognition. Finally, categorisation has been put forward as a potential problem for phonemic representation, but it could also play a role in other domains, such as syntax, semantics and even pragmatics.

\section{Relations between SLI and advances in neurological research}

A second major issue for future research on SLI is the capacity to link research on language impairment with up to date proposals about language and the brain. In the same way that we have argued for including non-specific language impairments in the framework of SLI categorisation, diagnosis and remediation, so do we argue for pursuing the relationship with advances and research in brain neurology. The sooner research will make the link between SLI and the brain, the better it will understand language impairments. A detailed analysis of how language works in the brain and which functions are most likely to be impaired in children with SLI is beyond the goal of this paper. Our intent here is only to present some of the most promising issues on the subject.

The available studies on correlates of language impairment suggest that 'impaired language development is correlated with abnormalities in the neuropsysiological patterns of differents aspects of language processing and with abnormalities in the structures of areas known to support language processes in healthy adult brain', (Friederici, 2006, p. 949). Event-related potential (ERP) studies performed in children with SLI indicate that these children already fail to show normal age adequate ERP patterns in their first months of life. For example, they present a massively delayed mismatch response for discrimination of syllable duration, an important measure in phonological processes (Manuela \& Angela, 2004; Weber, Hahne, Friedrich, \& Friederici, 2004) - see also Bishop (2007) for a review. Deficit in lexical-semantic processes was also noted: the N400 (a negative going wave form peaking around $400 \mathrm{~ms}$ correlating with 
lexical-semantic processes) appeared to be absent in 10- to 12-year-old children with SLI in response to a semantic violation, whereas control children showed a clear N400 component. However, another ERP study with 12- to 14-year-old children with a selective grammatical impairement (G-SLI, H. K. J. van der Lely, 1998) indicate that these children presented an N400 in relation to semantic aspects of processing whereas they did not present the syntax-related component ELAN found on control children in case of syntactic violation (Fonteneau \& van der Lely, 2008).

Some studies tried to assess the brain basis of SLI. They suggested that different subgroups of deficits could be found. First, structural abnormalities in the superior temporal gyrus (the planum temporale in particular, see C. M. Leonard et al., 2002) seemed to be related to deficit in temporal auditory processing observed behaviorally or in ERP studies. Second, abnormalities in the left inferior frontal cortex were also found, even if the functional aspects of these structural abnormalities is not yet clearly demonstrated. Detailed fMRI studies in normal children are needed. Third, fMRI studies on the KE family, a family well-known for presenting a severe form of verbal apraxia (Hurst, Baraitser, Auger, Graham, \& Norrell, 1990) reported abnormalities in the basal ganglia (caudate nucleus and putamen). These structures are crucial for controlling and selecting motor sequences necessary for articulation. To our knowledge, the ERP or fMRI studies made on children with SLI did not concern other topics than language abilities. It is thus difficult to conclude that all abnormalities were documented.

It is also interesting to try to link known areas of difficulties for children with SLI with upto-date research results about the brain. The first candidate for such a link is the children's difficulty with memory. Behavioural studies suggest potential problems with working memory, procedural memory and long-term memory. These systems are also referred to as short-term explicit memory, long-term implicit memory and long-term explicit memory (Smith \& 
Grossman, 2008). There are still many views regarding the logical and neurological organisation of the memory system. A common view is that these systems have different implementations in the brain (Maddox \& Ashby, 2004) and that they develop at different rates (Thomas et al., 2004). Working memory is not considered a monolithic structure (Baddeley, 2003; Collette \& Linden, 2002; Richardson, 2007) and its various properties suggest the existence of a variety of possible neurological deficits (McDonald, Devan, \& Hong, 2004; Mizumori, Yeshenko, Gill, \& Davis, 2004; Poldracka \& Rodriguez, 2004). Some studies tried to link deficits in specific memory systems with language deficits (Nicolson, Fawcett, \& Dean, 2001; Ullman \& Pierpont, 2005), but it is unlikely that such simple relation will hold for all types of deficits. Another hypothesis is that subtle disorders in the development of the various memory systems impair the balance between them. For example, performances in rule-based and information-integration structures differ depending on whether children possess high or low working memory capacities (DeCaro, Thomas, \& Beilock, 2008). The timing in the development of the different components of memory could disrupt the normal development of language. Late development of a component may not always allow returning to normal functioning, as the late developing component could be inhibited by other components which, in turn, would not be that advanced in normal development. Language performances would be more subject to this kind of problem because it is a large system based on multiple capacities. Another possibility is that, as is the case with brain disorders, a localised severe deficit creates fewer problems than a non-localised deficit (Locke, 1997). Disruption of the development and interrelations between components of the cognitive systems could be more difficult to overcome than the permanent and severe deficit of a single component.

An important question about the nature of the deficits in language development is why should specific language impairments exist? The question is even more important if language 
deficits are linked to deficits in other cognitive domains. What makes language so special that it is more complex and more liable to deficiencies than other cognitive abilities?

A tentative answer resides in the existence of recursive processes in the brain. This feature is a permanent and remarkable aspect of language processes, at least where slightly complex language behaviour is expected. This necessity for recursion could be much less of a problem in other cognitive domains. It would be interesting to test whether recursion problems are also found in other domains in children with language deficits. An interesting aspect of recursion is that it might be linked to characteristics of processing complexity, which is a known problem in dysphasic children (Bortolini, Leonard, \& Caselli, 1998; Parisse \& Maillart, in press). Pulvermüller (2002) makes a proposal concerning the implementation of a recursion mechanism in the brain. The proposal is that some specific lexical cues, such as for example relative pronouns, trigger off the regulation mechanism of the brain assigned to limiting its global activity. The regulation mechanism changes then its behaviour and suddenly lowered all activity in the brain, thus allowing the processing of another imbricate language structure on top of all previous brain activities without brain over activation. Without this mechanism which allows regulation of processing complexity in the brain, recursion is impossible. Another brain feature is hypothesised by Pulvermüller (2002). It is the fact that multiple concurrent states are allowed in a neural network: in other words, that the same neural sequence may be activated simultaneously, but at different activation levels. The same word or the same grammatical construction can be processed in more than one exemplar at the same time - for a proposal about grammatical constructions in the brain, see Pulvermüller (2002; Pulvermüller, 2003). These mechanisms are not necessarily specific to language, so that if they are impaired, other recursive features outside language should also be impaired (such a prediction, if it was confirmed, could be an important confirmation of the hypothesis of recursive computation limitation). Our theory is that such 
features are not frequent outside of the language domain, which explains language specificity of impairments. Furthermore, these two mechanisms underline the logical link that exists between recursion (especially in language) and processing complexity, as recursion calls for simultaneous processing, which is obviously much more complex in terms of brain mechanisms regulation as well as the number of simultaneous neural processes involved. This hypothesis of a link between complexity and recursion does not preclude the existence of other links to complexity problems. For example, difficulties with complex memory activities have been linked to impairment in verbal memory (Archibald \& Gathercole, 2007).

\section{Conclusion}

One question remains: why use a classification of the different types of dysphasia instead of looking directly at the real causes of the trouble? This would, of course, be the better option. One would simply run a large battery of tests, find out precisely what is wrong and proceed with medical treatment. Unfortunately, this is not possible with most problems affecting high-level cognitive functions such as SLI, because of the compensation properties of the system. Rarely can a cause be singled out. At best, it might be possible to find a set of causes and treat the problems. SLI would disappear from the pathological classification and be replaced by sets of pathological abilities, defined by one or more associated impaired abilities. But even this is often not possible. Some functions may be impaired but compensated for by other closely related functions. The converse is also possible. A particular function may not be compensated for because other related functions are also impaired. This means that the system should also be

considered as a whole before deciding what is important for remediation. For this reason, a systemic view remains more efficient. Within the framework presented in this paper, diagnosis of SLI would involve two steps: (1) categorise the children into one of the three syndromes; (2) find 
out which abilities are deficient for the specific syndrome. Then remediation would take place, either building on the child's strong points, or trying to rebuild the deficient abilities, depending on the specificities of the child and the remediation process. Hopefully, using results from nonlinguistic tests would help to focus the remediation process, especially in complex and difficult cases.

Our proposal is the outcome of results from clinical practice, from contradictory evidence in the literature that imply that no cause for SLI can be singled out, and from the many results in the literature concerning links between language deficits and poor non-linguistic abilities. This proposal has two immediate implications that can be used to test its correctness and hopefully demonstrate its soundness. The first is that there will always be some clear-cut differences in the non-linguistic performances of children diagnosed as having the three different types of SLI presented in this article, if not necessarily between the types of dysphasia presented in other frameworks. The second is that it should be possible to find three sets of characteristics (linguistic or non-linguistic) that reliably characterise the three types of SLI proposed here. Finally, as these three main categories of SLI correspond to three different types of behaviours, which are selectively impaired in children with SLI, they should correspond to distinct sub-systems of the human cognitive system and thus to sub-systems of the brain. If this is the case, future work based on brain imagery should tell us whether the classification we suggest in this paper is corroborated by actual neurological organisations. 


\section{References}

Adams, A.-M., \& Gathercole, S. E. (2000). Limitations in working memory: implications for language development. International Journal of Language \& Communication Disorders, 35(1), 95-116.

Archibald, L. M. D., \& Gathercole, S. E. (2007). The complexities of complex memory span: Storage and processing deficits in specific language impairment. Journal of Memory and Language, 57(2), 177-194.

Baddeley, A. (2003). Working memory and language: an overview. Journal of Communication Disorders, 36(3), 189-208.

Bavin, E. L., Wilson, P. H., Maruff, P., \& Sleeman, F. (2005). Spatio-visual memory of children with specific language impairment: evidence for generalized processing problems. International journal of language communication disorders, 40(3), 319-332.

Bishop, D. V. M. (1992). The underlying nature of specific language impairment. Journal of Child Psychology and Psychiatry, 33, 3-66.

Bishop, D. V. M. (2004). Specific language impairment: diagnostic dilemmas. . In L. Verhoeven \& H. Van Balkom (Eds.), Classification of Developmental Language Disorders (pp. 309326). Mahwah, N. J.: Erlbaum.

Bishop, D. V. M. (2006). What causes specific language impairment in children? Current Directions in Psychological Science, 15, 217-221.

Bishop, D. V. M. (2007). Using mismatch negativity to study central auditory processing in developmental language and literacy impairments: Where are we, and where should we be going? Psychological Bulletin 133(4), 651-672.

Bishop, D. V. M., Bright, P., James, C., Bishop, S. J., \& Van der Lely, H. K. J. (2000). Grammatical SLI : a distinct subtype of developmental language impairment ? Applied Psycholinguistic, 21(2), 159-181.

Bishop, D. V. M., Carlyon, R. P., Deeks, J. M., \& Bishop, S. J. (1999). Auditory temporal processing impairment: neither necessary nor sufficient for causing language impairment in children. Journal of Speech, Language and Hearing Research, 42(6), 1295-1310.

Bishop, D. V. M., \& Edmunson, A. (1987). Language-impaired four-year-olds: distinguishing transient from persistent impairment. Journal of Speech and Hearing Disorders, 52, 156173.

Bishop, D. V. M., North, D., \& Donlan, C. (1996). Nonword repetition as a behavioural marker for inherited language impairment : evidence from a twin study. . Journal of Child Psychology and Psychiatry, 36, 1-13.

Bishop, D. V. M., \& Rosenbloom, L. (1987). Classification of childhood language disorders. In W. Yule \& M. Rutter (Eds.), Language Development and Disorders. Clinics in Developmental Medicine (double issue) (pp. 101-102). London: MacKeith Press.

Bortolini, U., Leonard, L. B., \& Caselli, M. C. (1998). Specific language impairment in Italian and English: Evaluating alternative accounts of grammatical deficits. Language and Cognitive Processes, 13(1), 1-20.

Botting, N., \& Conti-Ramsden, G. (2004). Characteristics of Children with Specific Language Impairment. In L. Verhoeven \& H. Van Balkom (Eds.), Classification of Developmental Language Disorders (pp. 23-38). Mahwah, N.J.: Erlbaum.

Botting, N., \& Conti Ramsden, G. (2001). Non-word repetition and language development in children with specific language impairment (SLI). International journal of language communication disorders, 36(4), 421-432. 
Coady, J. A., Kluender, K. R., \& Evans, J. L. (2005). Categorical perception of speech by children with specific language impairments. Journal of Speech, Language and Hearing Research, 48(944-959).

Collette, F., \& Linden, M. V. d. (2002). Brain imaging of the central executive component of working memory. Neuroscience and Biobehavioral Reviews, 26, 105-125.

Conti-Ramsden, G., Botting, N., \& Faragher, B. (2001). Psycholinguistic markers for Specific Language Impairment. . Journal of Child Psychology and Psychiatry, 42, 741-748.

Conti-Ramsden, G., Crutchley, A., \& Botting, N. (1997). The extent to which psychometric tests differentiate subgroups of children with SLI. Journal of Speech, Language, and Hearing Research, Hearing-Research.

Criddle, M. J., \& Durkin, K. (2001). Phonological representation of novel morphemes in children with SLI and typically developing children. Applied Psycholinguistics, 22, 363-382.

DeCaro, M. S., Thomas, R. D., \& Beilock, S. L. (2008). Individual differences in category learning: Sometimes less working memory capacity is better than more. Cognition, 107(1), 284-294.

Eimas, P. D., Siqueland, E. R., Jusczyk, P. W., \& Vigorito, J. (1971). Speech perception in infants. Science, 171, 303-306.

Ellis Weismer, S., Evans, J., \& Hesketh, L. (1999). An examination of verbal working memory capacity in children with specific language impairment. . Journal of Speech. Language and Hearing Research, 42, 1249-1260.

Ellis Weismer, S., Plante, E., Jones, M., \& Tomblin, J. B. (2005). A functional magnetic resonance imaging investigation of verbal working memory in adolescents with specific language impairment. Journal of Speech, Language and Hearing Research, 48, 405-425.

Fey, M. E., \& Loeb, D. F. (2002). An evaluation of the facilitative effects of inverted yes-no questions on the acquisition of auxiliary verbs. Journal of Speech Language and Hearing Research, 45(1), 160-174.

Fey, M. E., Long, S. H., \& Cleave, P. L. (1994 ). Reconsideration of IQ criteria in the definition of specific Language Impairment. In R. V. Watkins \& M. L. Rice (Eds.), SLI in children. (pp. 161-178). Baltimore Paul H. Brookes Publishing.

Fonteneau, E., \& van der Lely, H. K. J. (2008). Electrical Brain Responses in Language-Impaired Children Reveal Grammar-Specific Deficits.):. PLoS ONE 3(3)( e1832.doi:10.1371/journal.pone.0001832).

Friederici, A. D. (2006). The Neural Basis of Language Development and Its Impairment. Neuron, 52, 941-952.

Hauser, M. D., Chomsky, N., \& Fitch, W. T. (2002). The faculty of language: what is it, who has it, and how did it evolve? Science, 298, 1569-1579.

Hick, R., Botting, N., \& Conti-Ramsden, G. (2005). Cognitive abilities in children with specific language impairment: consideration of visuo-spatial skills. International Journal of Language \& Communication Disorders, 40(2), 137-149.

Hiskey, M. S. (1966). The Hiskey-Nebraska Test of Learning Aptitude Manual (Revised). Baldwin Lincoln Nebraska.

Howard, J. H. J., Howard, D. V., Japikse, K. C., \& Eden, G. F. (2006). Dyslexics are impaired on implicit higher-order sequence learning, but not on implicit spatial context learning. Neuropsychologia, 44, 1131-1144.

Hurst, J. A., Baraitser, M., Auger, E., Graham, F., \& Norrell, S. (1990). An extended family with a dominantly inherited speech disorder.

. Dev. Med. Child Neurol., 32, 347-355. 
Jarrold, C., Baddeley, A. D., \& Hewes, A. K. (2000). Verbal short-term memory deficits in Down Syndrome : a consequence of problems in rehearsal ? . Journal of Child Psychology and Psychiatry, 41, 233-244.

Jusczyk, P. W., Rosner, B. S., Cutting, J. E., Foard, C. F., \& Smith, L. B. (1977). Categorical perception of nonspeech sounds by 2-month-old infants. Perception and Psychophysics, 21, 50-54.

Karlsson, F. (2007). Constraints on multiple initial embedding of clauses. International Journal of Corpus Linguistics, 12(1), 107-118.

Korkman, M., \& Hakkinen-Rihu, P. (1994). A new classification of developmental language disorders (DLD). Brain and Language, 47(1), 96-116.

Leonard, C. M., Lombardino, L. J., Walsh, K., Eckert, M. A., Mockler, J. L., Rowe, L. A., et al. (2002). Anatomical risk factors that distinguish dyslexia from SLI predict reading skill in normal children. . Journal of Communication Disorders, 35, 501-531.

Leonard, L. B., Weismer, S. E., Miller, C. A., Francis, D. J., Tomblin, J. B., \& Kail, R. V. (2007). Speed of processing, working memory, and language impairment in children. Journal of Speech, Language and Hearing Research, 50, 408-428.

Locke, J. L. (1997). A theory of neurolinguistic development. Brain and Language, 58, 265-326.

Maddox, W. T., \& Ashby, F. G. (2004). Dissociating explicit and procedural-learning based systems of perceptual category learning. Behavioural Processes, 66(3), 309-332.

Manuela, F., \& Angela, D. F. (2004). N400-like Semantic Incongruity Effect in 19-Month-Olds: Processing Known Words in Picture Contexts. Journal of Cognitive Neuroscience, 16(8), 1465-1477.

McArthur, G. M., \& Bishop, D. V. M. (2002). Temporal resolution and frequency discrimination in people with a specific language impairment: Behavioural and electrophysiological evidence. In S. Hawkins \& N. Nguyen (Eds.), Temporal integration in the perception of speech. Cambridge, UK: The Reprographic Centre.

McArthur, G. M., \& Bishop, D. V. M. (2004). Which people with specific language impairment have auditory processing deficits? Cognitive Neuropsychology, 21, 79-94.

McDonald, R. J., Devan, B. D., \& Hong, N. S. (2004). Multiple memory systems: The power of interactions. Neurobiology of Learning and Memory, 82, 333-346.

Mizumori, S. J. Y., Yeshenko, O., Gill, K. M., \& Davis, D. M. (2004). Parallel processing across neural systems: Implications for a multiple memory system hypothesis. Neurobiology of Learning and Memory, 82, 278-298.

Montgomery, J. W. (2000). Relation of working memory to off-line and real-time sentence processing in children with specific language impairment. Applied Psycholinguistics, 21, $117-148$.

Montgomery, J. W. (2003). Working memory and comprehension in children with specific language impairment: what we know so far. Journal of Communication Disorders, 36, 221-231.

Montgomery, J. W., \& Windsor, J. (2007). Examining the language performances of children with and without specific language impairment: contributions of phonological short-term memory and speed of processing. Journal of Speech, Language and Hearing Research, 50, 778-797.

Morse, P. A., Molfese, D., Laughlin, N. K., Linnville, S., \& Wetzel, F. (1987). Categorical perception for voicing contrasts in normal and lead-treated rhesus monkeys: Electrophysiological indices. Brain and Language, 30(1), 63-80. 
Nicolson, R. I., \& Fawcett, A. J. (2000). Long-term learning in dyslexic children. European Journal Of Cognitive Psychology, 12(3), 357-393.

Nicolson, R. I., Fawcett, A. J., \& Dean, P. (2001). Developmental dyslexia: the cerebellar deficit hypothesis. Trends in Neurosciences, 24(9), 508-511.

Paradis, J., \& Crago, M. (2000). Tense and Temporality : a comparison between children learning a second language and children with SLI. Journal of Speech, Language and Hearing Research, 43, 834-847.

Parisse, C., \& Maillart, C. (in press). The interplay between phonology and syntax in Frenchspeaking children with specific language impairment. International Jounal of Language and Communication Disorders.

Poldracka, R. A., \& Rodriguez, P. (2004). How do memory systems interact? Evidence from human classification learning. Neurobiology of Learning and Memory, 82, 324-332.

Pulvermüller, F. (2002). The neuroscience of language. Cambridge Cambridge University Press.

Pulvermüller, F. (2003). Sequence Detectors as a Basis of Grammar in the Brain. Theory in Biosciences, 122(1), 87-103.

Rapin, I., \& Allen, D. A. (1983). Developmental language disorders: Nosologic considerations. In U. Kirk (Ed.), Neuropsychology of language, reading, and spelling (pp. 155-184). New York: Academic.

Rice, M. L., \& Wexler, K. (1995). Extended optional infinitive (EOI) account of specific language impairment. In D. MacLaughlin \& S. McEwan (Eds.), Proceedings of the 19th annual Boston University Conference on Language Development, Vol. 2 (pp. 451-462). Somerville, MA: Cascadilla Press.

Richardson, J. T. E. (2007). Measures of Short-Term Memory: A Historical Review. Cortex, 43(5), 635-650.

Serniclaes, W., Van Heghe, S., Mousty, P., Carré, R., \& Sprenger-Charolles, L. (2004). Allophonic mode of speech perception in dyslexia. Journal of Experimental Child Psychology(87), 336-361.

Smith, E. E., \& Grossman, M. (2008). Multiple systems of category learning. Neuroscience \& Biobehavioral Reviews, 32(2), 249-264.

Tallal, P., Stark, R. E., \& Mellits, D. U. (1985). The relationship between auditory temporal analysis and receptive language development: Evidence from studies of developmental language disorder. Neuropsychologia, 23(4), 527-534.

Thomas, K. M., Hunt, R. H., Vizueta, N., Sommer, T., Durston, S., Yang, Y., et al. (2004). Evidence of developmental differences in implicit sequence learning: an fMRI study of children and adults. Journal of Cognitive Neuroscience, 16(8), 1339-1351.

Tomblin, J. B., \& Zhang, X. (1999). Language patterns and etiology in children with specific language impairment. I. In H. Tager-Flusberg (Ed.), Neurodevopmental disorders (pp. 361-382). Cambridge, MA: MIT Press / Bradford Books.

Ullman, M. T., \& Pierpont, E. I. (2005). Specific language impairment is not specific to language: the procedural deficit hypothesis. Cortex; a Journal Devoted To The Study Of The Nervous System And Behavior, 41(3), 399-433.

van der Lely, H. K. J. (1998). SLI in children: Movement, economy, and deficits in the computational-syntactic system. Language Acquisition, 7, 161-192.

van der Lely, H. K. J. (1999). Learning from Grammatical SLI. Trends in Cognitive Sciences, 3(8), 286-288. 
van der Lely, H. K. J., \& Ullman, M. (2001). Past tense morphology in specifically language impaired and normally developing children. Language and Cognitive Processes, 16(2/3), $177-217$.

Weber, C., Hahne, A., Friedrich, M., \& Friederici, A. D. (2004). Discrimination of word stress in early infant perception: Electrophysiological evidence. Cognitive Brain Research, 18, 149-161.

Webster, R. I., Erdos, C., Evans, K., Majnemer, A., Kehayia, E., Thordardottir, E., et al. (2006). The clinical spectrum of developmental language impairment in school-aged children: language, cognitive, and motor findings. Pediatrics, 118(5), e1541-1549.

Webster, R. I., Majnemer, A., Platt, R. W., \& Shevell, M. I. (2005). Motor function at school age in children with a preschool diagnosis of developmental language impairment. The Journal of Pediatrics, 146(1), 80-85. 